\title{
Redesign Interior in Yulia 1 Homestay, Sanur, Denpasar Selatan, Bali Application of Scandinavian Concepts
}

\author{
I Gede Eka Prasetya $^{1}$, I Wayan Wiryawan ${ }^{2}$ \\ Bachelor Degree of Architecture Study Program \\ Faculty of Engineering-Udayana University \\ Jimbaran \\ prasetyaeka546@gmail.com \\ Architecture Study Program \\ Faculty of Engineering-Udayana University \\ Jimbaran
}

\begin{abstract}
Tourism in Bali is an important economic sector for the people of Bali. Tourism is synonymous with an lodging. In every place, especially tourist destinations, there must be many lodging facilities. Sanur as one of the tourist destinations cer-tainly has many choices of lodging places such as homestays, competition between homestays in attracting interested local and foreign guests is getting tighter. The bedroom and bathroom are the most important part of a homestay. In de-signing space in the bedroom and bathroom of Yulia 1 Homestay Sanur uses the Scandinavian Concept in the hope of giving a different identity than other homestays without reducing comfort. The Scandinavian concept has a neutral color and simple character in the selection of furniture.
\end{abstract}

Index Terms - interior design, homestay, bedroom, bathroom, scandinavian.

\section{INTRODUCTION}

Bali is a tourist destination that is famous for its natural beauty, customs and arts and culture. Of the tourism potential possessed by Bali, making Bali must provide good facilities in meeting the needs of tourists both local and foreign. Lodging is one of the main needs for tourists visiting Bali, the type of lodging is distinguished from largescale ones such as hotels to small-scale ones such as homestays.

Homestay is an ordinary house that has rooms for rent to tourists who need lodging for some time and they live in the same house with their owners. Homestay owners generally do not provide other facilities besides bedrooms and equipment. Tourists who stay at the homestay are mostly backpackers or tourists who travel with a limited budget but are also not closed to tourists who are bored with the atmosphere of the hotel, because homestays have a sense of family because they live together with their owners.

Sanur as a tourist destination certainly has many homestays, the development of homestays in the Sanur area is getting higher because the surrounding community is aware of the opportunities that exist. Can be seen along the main roads in the Sanur area there are many homestays ranging from those located on the main road to the remote areas there are also homestays, the number of homestays certainly makes the competition tighter both in price competition and facilities. The tight competition makes a homestay must have a distinctive design in order to give a different impression compared to others.

The bedroom and bathroom are the main facilities in a homestay. The level of customer satisfaction is determined based on the quality of the main facilities provided but apart 
from the mentioned quality of friendly service will also certainly support the level of customer satisfaction. In an effort to achieve customer satisfaction, we need the main facilities that can bring a comfortable and friendly atmosphere, we need an approach to color and material. The Scandina-vian concept is a concept that emphasizes the characteristics of a simple design with neutral colors and emphasizes function so that it can be accepted by all ages.

\section{RESULT AND ANALISYS}

\section{A. Object}

Yulia 1 Homestay is a homestay located on Jalan Danau Tamblingan No. 38 Sanur, Denpasar Selatan. Yulia 1 Homestay is $2 \mathrm{~km}$ from Sanur Beach, $4 \mathrm{~km}$ from Mertasari Beach, $7 \mathrm{~km}$ from Denpasar City and $16 \mathrm{~km}$ from I Gusti Ngurah Rai Airport. Yulia 1 Homestay is on the main road where many tourists travel so it can be used as a potential. In addition, the object is also adjacent to restaurants, pharmacies and night markets.

Based on observations, Yulia 1 Homestay has 29 number of rooms which are divided into four room types namely, 1) Standard Room, 2) Standard Room with Hot Water, 3) Superior Room and 4) Deluxe Room. Each room type has an area and facilities that differ from one another, in the design of using the Deluxe Room as an object of the Scandinavian concept application in the bedroom and bathroom. Deluxe Room was chosen because it has the most complete facilities compared to other room types.

In the homestay there are also supporting facilities such as swimming pool and restaurant, the swimming pool is located in the middle while the restaurant is located next to the swimming pool, the restaurant at Yulia 1 Homestay is only used as a place for guests to order and enjoy breakfast.

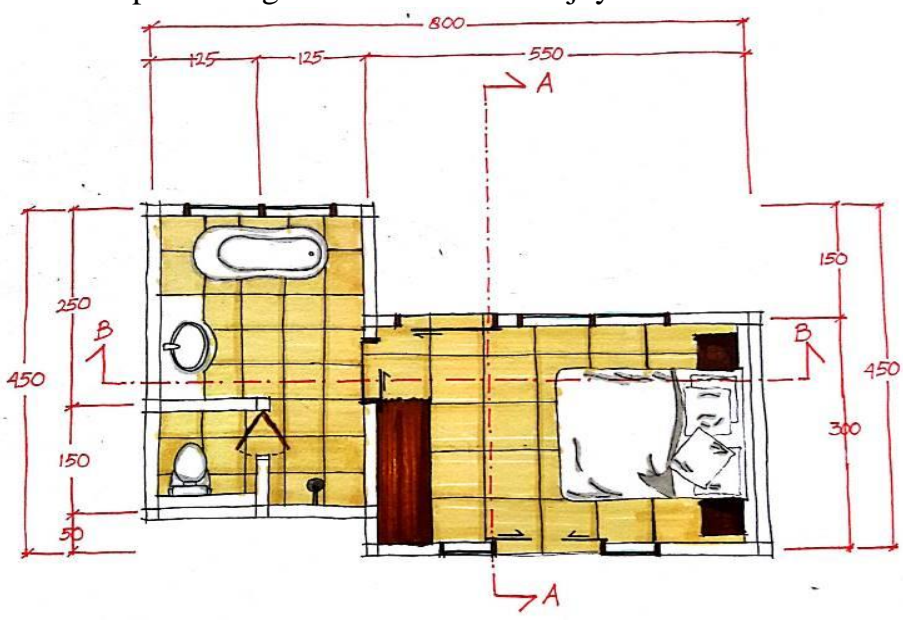

Fig. 1. Plan Exsisting (source: Prasetya:2017)

The Deluxe Room at Yulia 1 Homestay has a dimension of $32 \mathrm{~m} 2$ with openings in the form of sliding doors to the North and South of the bedroom. Existing facilities in the Deluxe Room are, 1) Hot Water, 2) Air Conditioning, 3) $\mathrm{TV}, 4)$ Refrigerator and 5) Bathub. In the bedroom and bathroom area there are many openings in order to maximize air circulation and incoming light so as to reduce the use of artificial lighting and ventilation in addition to that the openings are also functioned so that the room feels more spacious.

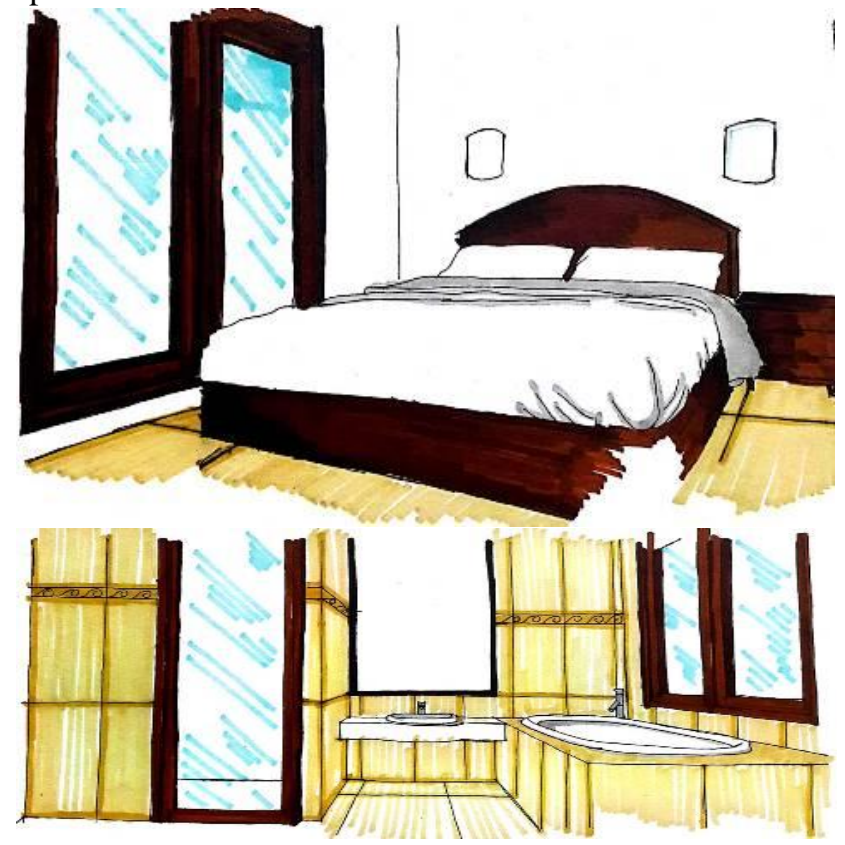

Fig. 2. Interior Perspective (source: Prasetya:2017)

\section{B. Scandinavian Concept}

Scandinavian is a concept originating from Eastern European countries such as, Norway, Sweden, Den-mark, Iceland and Finland. The Scandinavian concept was introduced at design exhibitions in America and Canada around the 1950s. Scandinavian concept is known as a beautiful concept, simple, clean, and inspired by nature, easily accessible and available to all people. Scan-dinavian designers are more interested in producing products that are functional, durable and have efficient prices. Scandinavian concept is widely applied in Western countries, because this interior concept focuses on simplicity, the utilization of each room while still looking elegant and beautiful. In principle, the Scandinavian concept prioritizes functionality without losing its beauty and elegance. Scandinavian concept is widely applied in Western countries, mainly because this interior design focuses on simplicity, the utilization of each room while still looking elegant and beautiful. Good lighting is a very important element of the Scandinavian concept. Lighting is expected to give a warm and comfortable impression to the room [1].

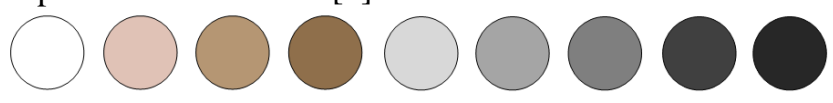

Fig. 3. Scandinavian Color Palette (source: Prasetya:2017)

The Scandinavian concept has several characteristics or characteristics, namely, 1) Using wood floors with bright colors with the aim of giving the impression of wide and warm in the room, 2) Using natural colors such as white, gray and beige so that it can be said to use plain colors and unobtrusive, 3) More emphasis on function, 4) Simple 
furniture design, 5) Large windows for natural lighting and ventilation and 6) Integrated with nature.

\section{Application of Scandinavian Concept}

To create a room that is relieved, the colors used are light colors to classify the dimensions of the room so that the room does not feel stuffy and tight. The color used is predominantly white in accordance with the Scandinavian concept. In the bedroom the dark gray color was chosen on the wall of the backdrop of the bed intended as a point of interest in the room so as to avoid the impression of a monotonous room, the dark gray color was chosen because it was still classified as a light color and in accordance with the characteristics of the Scandinavian concept. Whereas in the bathroom using ceramics with white in order to display a clean impression on the bathroom wall. Besides the addition of some artwork such as paintings on the bedroom backdrop and the addition of vegetation on the bedroom and bathroom gives more appeal to the room.

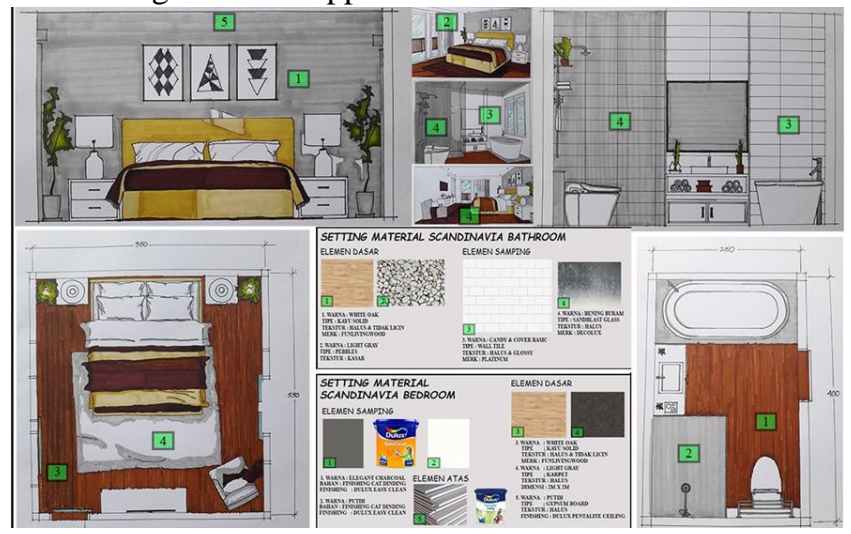

Fig. 4. Scandinavian Concept Material Settings in the Deluxe Room Interior (source: Prasetya:2017)

The basic elements in the bedroom use white oak wood flooring so that it can still give a natural and warm impression to the room so that guests who are resting still feel comfortable. In the basic elements of the bathroom also uses wooden floors in the dry area and in the wet area using white pebbles with the aim of giving the impression of nature. The form of furniture used has a simple form and emphasizes the function in accordance with the Scandinavian concept. The combination of basic elements, side elements and furniture gives the impression of clean, warm and natural in the bedroom and bathroom.

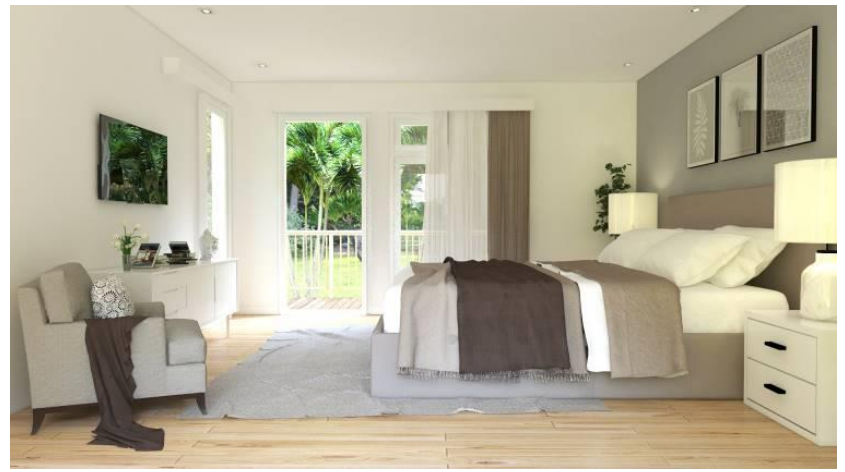

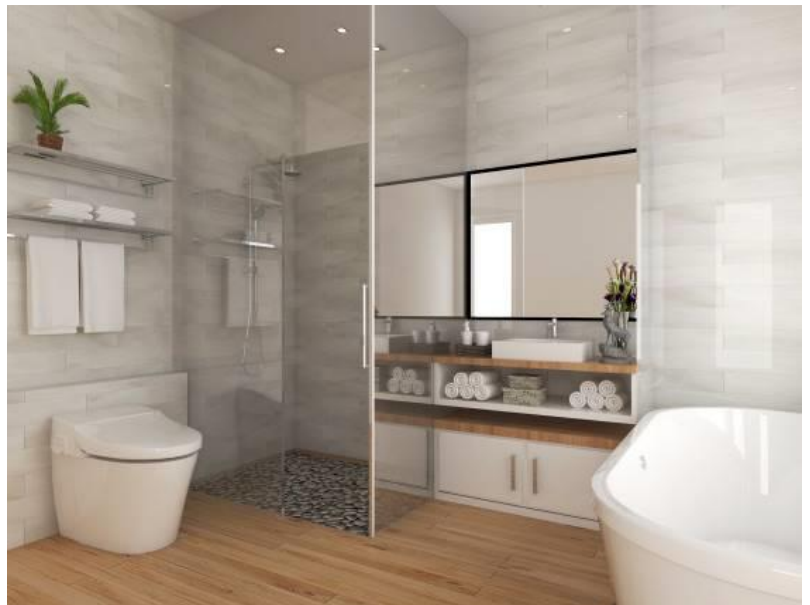

Fig. 5. Scandinavian Concept Material Settings in the Deluxe Room Interior (source: Prasetya:2017)

In Figure 4 is a visualization of the application of the Scandinavian concept in the Deluxe Room Interior. Can be seen in the bedroom using neutral colors to make the room look spacious and clean, the shape of the furniture is more concerned with function and at the entrance of the Deluxe Room there is a sliding door with dimensions large enough to maximize the incoming light. In the bathroom also uses neutral colors with different uses of elements in dry areas using wood floors while in wet areas using white pebbles.

\section{CONCLUSION}

Scandinavian concept is widely applied in Western countries, mainly because this interior design focuses on simplicity, the utilization of each room while still looking elegant and beautiful. Scandinavian concept is a concept that emphasizes the characteristics of a simple design with neutral colors and emphasizes the function so that it can be accepted by all ages. The Scandinavian concept has several characteristics or characteristics, namely, To create a room that is relieved, the colors used are light colors to classify the dimensions of the room so that the room does not feel stuffy and tight. The color used is predominantly white in accordance with the Scandinavian concept. In the bedroom the dark gray color was chosen on the wall of the backdrop of the bed intended as a point of interest in the room so as to avoid the impression of a monotonous room, the dark gray color was chosen because it was still classified as a light color and in accordance with the characteristics of the Scandinavian concept; 1) Using wood floors with bright colors, 2) Using natural colors such as white, gray and beige, 3) More emphasis on function, 4) Simple furniture design, 5) Large windows for natural lighting and 6) Integrated with nature. The application of the Scandinavian concept to the interior of the Deluxe Room at Yulia 1 Homestay is expected to be unique so that guests who stay in feel a different atmosphere without reducing comfort so that Yulia 1 Homestay is able to compete in the accommodation sector. 
Journal of a Sustainable Global South, p-ISSN: 2579-6062

\section{REFERENCES}

[1] Sarah J. Buckley, "Gentle Birth Gentle Mothering ”, One Moon Press 2005. 